\title{
Activation of microglial NADPH oxidase is synergistic with glial iNOS expression in inducing neuronal death: a dual-key mechanism of inflammatory neurodegeneration Palwinder Mander and Guy C Brown*
}

Address: Biochemistry Department, University of Cambridge, Tennis Court Road, Cambridge, CB2 1QW, UK

Email: Palwinder Mander - pkm22@cam.ac.uk; Guy C Brown* - gcb@mole.bio.cam.ac.uk

* Corresponding author

Published: 12 September 2005

Journal of Neuroinflammation 2005, 2:20 doi:10.1 186/1742-2094-2-20

This article is available from: http://www.jneuroinflammation.com/content/2/l/20

(c) 2005 Mander and Brown; licensee BioMed Central Ltd.

This is an Open Access article distributed under the terms of the Creative Commons Attribution License (http://creativecommons.org/licenses/by/2.0), which permits unrestricted use, distribution, and reproduction in any medium, provided the original work is properly cited.

Received: 25 July 2005

Accepted: I2 September 2005

\footnotetext{
which permits unrestricted use, distribution, and reproduction in any medium, provided the original work is properly cited.
} 


\section{Background}

Glia (microglia and astrocytes) can become inflammation activated in many CNS pathologies, including infectious, ischaemic, inflammatory and neurodegenerative disorders $[1,2]$. Glial activation may be protective to the host, as it can lead to the removal of cell debris and killing of pathogens [3]. However excessive or chronic glial activation can kill nearby neurons [4,5]. Thus inflammation may contribute to many CNS pathologies including Alzheimer's, Parkinson's and motor neuron diseases, multiple sclerosis, meningitis, AIDS dementia, strokes, trauma and normal brain ageing $[6,7]$. It is therefore important to understand the mechanisms by which inflammatory-activated glia kill neurons.

Astrocytes and microglia can become activated by a range of factors, including pathogens and pro-inflammatory cytokines, and can lead to the subsequent death of co-cultured neurons $[8,9]$. Activated astrocytes and/or microglia produce a variety of factors which can mediate neuronal death, including reactive oxygen species (ROS) $[10,11]$, nitric oxide $[8,9,12]$ and glutamate $[8,13]$, as well as proinflammatory cytokines that perpetuate glial activation, such as interleukin-1 $\beta$ (IL-1 $\beta$ ) and tumour necrosis factor$\alpha(\mathrm{TNF}-\alpha)[14]$.

The neuroprotective effects of anti-oxidants have been established [15] and are thought to be due to the removal of ROS (such as superoxide) and as well as more toxic molecules (such as peroxynitrite) [16]. There is evidence that NADPH oxidase is activated in Alzheimer's disease and AIDS dementia [17-19]. The major source of ROS during inflammation is NADPH oxidase $[20,21]$, although other sources may also contribute [22,23]. NADPH oxidase is expressed mainly by microglia in the brain $[21,24]$, and produces superoxide $\left(\mathrm{O}_{2}^{-}\right)$extracellularly or within phagocytic vesicles, in order to kill pathogens. The oxidase can be acutely activated by PMA, ATP, arachidonic acid, some chemokines and cytokines [2528]. Superoxide is then broken down mainly by extracellular and intracellular superoxide dismutase to give hydrogen peroxide $\left(\mathrm{H}_{2} \mathrm{O}_{2}\right)$.

iNOS is not normally expressed in the brain, but is induced in astrocytes and microglia by proinflammatory cytokines and pathogen components, such as lipopolysaccharide (LPS)/endotoxin of Gram-negative bacteria [29]. Once expressed iNOS produces high, sustained levels of NO which can, in certain conditions, kill nearby neurons, by mechanisms including inhibition of mitochondrial respiration and the release of glutamate from neurons and glia, resulting in excitotoxicity [8]. However, such mechanisms may require a relatively high level of $\mathrm{NO}$ and/or a relatively low level of oxygen [30,31]. An alternative mechanism would be for NO to react with superoxide (e.g. from the NADPH oxidase) to produce peroxynitrite (ONOO-), which is potentially more neurotoxic to neurons than $\mathrm{NO}$ or superoxide [32,33].

This suggests a dual-key hypothesis of inflammatory neurodegeneration whereby iNOS expression or NADPH oxidase activation alone is relatively benign, but when combined together at the same time causes neurodegeneration via peroxynitrite. We have previously shown that acute activation of the NADPH oxidase in isolated microglia expressing iNOS results in the rapid disappearance of $\mathrm{NO}$ and produces $\mathrm{ONOO}^{-}$[32]. In this paper we report that activation of the microglial NADPH oxidase to produce superoxide is synergistic with NO from iNOS in inducing death of co-cultured neurons, whereas activation of either alone causes little or no death of co-cultured neurons.

\section{Materials \& methods Materials}

The following materials were purchased from the indicated sources: 1400W.dihydrochloride from Alexis (Nottingham, UK); MK-801 maleate, apocynin and FeTPPS $(5,10,15,20$-Tetrakis(4-sulfonatophenyl)porphyrinato Iron (III) chloride) from Calbiochem (Nottingham, UK). All other reagents were ordered from Sigma (Poole, UK).

\section{Neuronal-glial culture}

Cerebellar granule cell (CGC) cultures were prepared from 7-day-old Wistar rats, as described in Bal-Price \& Brown, 2001. Briefly, the pups were anaesthetised using $5 \%$ halothane in oxygen, followed by decapitation. Brains were removed under sterile conditions and the cerebellum dissected. Meninges were removed and the cerebella dissociated in Versene solution (1:5000, Gibco BRL) and plated at $0.25 \times 10^{6}$ cells $/ \mathrm{cm}^{2}$ in 24 -well plates (in $500 \mu \mathrm{l}$ DMEM) coated with $0.001 \%$ poly-L-lysine. Cultures were maintained in DMEM (Gibco BRL) supplemented with $5 \%$ horse serum, 5\% foetal calf serum, $38 \mathrm{mM}$ glucose, 5 mM HEPES, $2 \mathrm{mM}$ glutamine, $25 \mathrm{mM} \mathrm{KCl}$ and $10 \mu \mathrm{g} / \mathrm{ml}$ gentamicin. Cells were kept at $37^{\circ} \mathrm{C}$ in a humidified atmosphere of $5 \% \mathrm{CO}_{2} / 95 \%$ air and used for experiments at 16-18 days in vitro (DIV). Cultures of CGC's contained $22 \pm 4 \%$ astrocytes and $2 \pm 1 \%$ microglia as assessed by immunocytochemistry using antibodies against glial fibrillary acidic protein (GFAP: a marker for astrocytes) and complement receptor-3 (a marker for microglia), CGC's were identified based on morphology and at 16-18 DIV $76 \pm 5 \%$ of the cells in the culture were CGC's. All experiments were undertaken in accordance with the UK Animals (Scientific Procedures) Act 1986.

\section{Activation of glia in neuronal-glial cultures}

Lipopolysaccharide (LPS), a cell wall component of Gram-negative bacteria and interferon- $\gamma$ (IFN- $\gamma$ ), a pro- 
inflammatory cytokine, are potent activators of glia when administered together. Neuronal-glial cultures were treated with $100 \mathrm{ng} / \mathrm{ml}$ LPS (from Salmonella typhimurium) and $10 \mathrm{ng} / \mathrm{ml}$ IFN- $\gamma$ (rat recombinant, Sigma) for 48 hours (or longer where indicated). The proinflammatory cytokines tumour necrosis factor- $\alpha$ (TNF- $\alpha ; 10 \mathrm{ng} / \mathrm{ml}$, rat recombinant, Sigma) and interleukin-1 $\beta$ (IL-1 $\beta ; 10 \mathrm{ng} /$ $\mathrm{ml}$, rat recombinant, Sigma) were also used in combination with IFN- $\gamma$ to activate the glia in neuronal-glial cultures ( 48 hours). Where present, inhibitors were added at the same time as LPS/IFN- $\gamma$.

In some experiments IL- $1 \beta$ or arachidonic acid (AA, 30 $\mu \mathrm{M}$ ) were added to the cultures as well as LPS/IFN- $\gamma$. In these experiments, IL- $1 \beta$ or AA were added 24 hours after LPS/IFN- $\gamma$ addition, but inhibitors were added at the same time as LPS/IFN- $\gamma$. Activators, inhibitors and IL- $1 \beta$ or AA were added once only and neuronal death was assessed 144 hours after LPS/IFN- $\gamma$ addition.

In some experiments, prion protein or a fragment of the human prion protein were used (kindly provided by David R. Brown, University of Bath). Recombinant mouse prion protein was expressed in bacteria and purified using a histidine-tagging method, as described previously [34]. The prion peptide (PrP106-126) with sequence KTNMKHMAGAAAAGAVVGGLG was derived from amino acid residues 106-126 of the human prion protein sequence, and a scrambled sequence of the peptide was used as a control; sequence: NGAKALMGGHGATKVMVGAAA. Prion protein was used at $5 \mu \mathrm{g} / \mathrm{ml}$ and the prion protein peptides at $225 \mu \mathrm{g} / \mathrm{ml}$.

To activate NADPH oxidase, phorbol 12-myristate 13-acetate (PMA, $50 \mathrm{ng} / \mathrm{ml}$ ) or benzoyl(benzoyl)-ATP (BzATP, 1 $\mathrm{mM}$ ) are used and are added to neuronal-glial cultures either alone or at the same time as LPS/IFN- $\gamma$.

\section{Enrichment of microglia in neuronal-glial cultures}

Primary rat microglia were obtained from mixed glial cultures (astrocytes and microglia). Glial cultures were prepared from the cerebral cortices of 7-day-old Wistar rats (the same brains that were used to isolate cerebellar granule neurons). Meninges were removed from the cerebral hemispheres and then dissociated using a solution of EBSS containing 0.3\% BSA, $0.004 \%$ DNase I and $0.025 \%$ Trypsin. Cells were plated at $0.1 \times 10^{6}$ cells $/ \mathrm{cm}^{2}$ in $75 \mathrm{~cm}^{2}$ cell culture flasks (Falcon) coated with $0.0005 \%$ poly-Llysine. Cultures were maintained in DMEM supplemented with $10 \%$ foetal calf serum and $1 \%$ PenicillinStreptomycin. Cells were kept at $37^{\circ} \mathrm{C}$ in a humidified atmosphere of $5 \% \mathrm{CO}_{2} / 95 \%$ air.

At confluency, glial cultures were used to isolate microglial cells by gently shaking/tapping the mixed glial cul- tures to dislodge microglia loosely attached to astrocytes. Medium from the mixed glial cultures, containing microglia was removed and centrifuged ( $135 \mathrm{~g}$ for 5 minutes). Microglia were re-suspended in conditioned medium from CGC cultures and added to neuronal-glial cultures in some experiments $\left(50,000\right.$ microglia $\left./ \mathrm{cm}^{2}\right)$. Fifteen minutes after the addition of microglia to some neuronalglial cultures, LPS/IFN- $\gamma$ and inhibitors where appropriate were added together. Neuronal death was assessed 48 hours after LPS/IFN- $\gamma$ addition.

\section{Assessment of glial activation}

Activation of glia in the neuronal-glial culture was assessed by NADPH diaphorase staining and measurements of nitrite in the medium. Nitric oxide synthase (NOS) is an NADPH diaphorase, using a chromogen (nitroblue tetrazolium, NBT), and NADPH as the reductant, diaphorase staining was used to detect cells with NOS activity. Following treatment (with cytokines or untreated for control staining) the neuronal glial cultures were fixed with $4 \%$ paraformaldehyde in phosphate buffer for 30 minutes at $4{ }^{\circ} \mathrm{C}$. After fixation, cells were incubated in 0.3\% Triton X-100 (in phosphate buffer) for 5 minutes. Cells were then incubated for 2 hours at $37^{\circ} \mathrm{C}$ in $0.3 \%$ Triton X-100 containing $1 \mathrm{mg} / \mathrm{ml} \mathrm{NADPH}$ and $0.2 \mathrm{mg} / \mathrm{ml}$ NBT. Cells were washed once with $0.3 \%$ Triton X-100 and then viewed using an inverted light microscope (Leica).

Nitrite levels in the medium were measured using the Griess reaction. Briefly, aliquots of medium following treatments were taken and centrifuged $(8000 \mathrm{~g}$ for $5 \mathrm{~min}$ utes). $6 \mathrm{mM} \mathrm{HCl}$ was added to the supernatant and then $1 \mathrm{mM}$ sulfanilamide and $1 \mathrm{mM} \mathrm{N}-1$ (1-naphthyl)ethylenediamine (NEDA) were added. Absorbance at a wavelength of $548 \mathrm{~nm}$ was measured by plate reader (BMG, Fluostar Optima), before and after the addition of NEDA. Nitrite concentrations in samples were calculated from a standard curve of sodium nitrite in DMEM.

\section{Assessment of cell viability}

The viability of CGC's was assessed by propidium iodide (PI, $2 \mu \mathrm{g} / \mathrm{ml})$ and Hoechst $33342(6 \mu \mathrm{g} / \mathrm{ml})$ staining, using a fluorescence microscope (Axiovert S-100) and filters for excitation at $365 \mathrm{~nm}$ and emission at $420 \mathrm{~nm}$. The cell-impermeable nuclear dye, PI stains the nuclei of cells that have lost plasma membrane integrity and are considered to be necrotic. Using the cell-permeable DNA dye Hoechst 33342, the nuclear morphology of the CGC's was studied. Neuronal nuclei exhibiting irregular Hoechst staining, nuclear shrinkage, chromatin condensation and/ or nuclear fragmentation but PI negative were classified as showing chromatin condensation (CC). Individual cells exhibiting both CC and PI staining were included in the PI data. Cells were counted in three microscopic fields in each well ( 3 wells per treatment) and expressed as a 
Table I: Effects of inflammatory activated-glia in mixed neuronal-glial cultures on neuronal death. Neuronal death was assessed by propidium iodide staining (PI, necrosis) or chromatin condensation of neuronal nuclei by Hoechst 33342 staining (CC, a marker of apoptosis) 48 hours after treatment. Nitrite (the primary breakdown product of NO) levels were measured in the culture medium 48 hours following treatments. Statistical differences were established using ANOVA at $* p<0.05$ and $* * *<<0.001$. Data expressed is mean \pm SEM, $n=3$ or more.

\begin{tabular}{cccc}
\hline TREATMENT & PI (\%) & CC (\%) & NITRITE ( $\mu$ M) \\
UNTREATED & $0.9 \pm 0.9$ & $0.5 \pm 0.6$ & $2.7 \pm 3.0$ \\
LPS/IFN- $\gamma$ & $5.7 \pm 3.4^{*}$ & $3.6 \pm 1.5 *$ & $18.6 \pm 8.4 * * *$ \\
TNF- $\alpha /$ IFN- $\gamma$ & $5.6 \pm 0.4 * * *$ & $4.3 \pm 2.9 *$ & $4.2 \pm 2.8$ \\
IL-I $\beta /$ IFN- $\gamma$ & $I .1 \pm 1.1$ & $0.6 \pm 0.7$ & $3.7 \pm 2.1$ \\
TNF- $\alpha /$ IL-I $/$ /IFN- $\gamma$ & $6.3 \pm 4.1 *$ & $5.5 \pm 3.2^{*}$ & $4.5 \pm 1.4$ \\
\hline
\end{tabular}

percentage of the total number of neurons. Each treatment was repeated at least three times.

\section{Assessment of microglia proliferation}

Microglia cells were identified using Isolectin $\mathrm{IB}_{4}$ (from Griffonia simplicifolia), which has strong affinity for microglia but not astrocytes. An Alexa Fluor 488 conjugate of isolectin $\mathrm{IB}_{4}(10 \mathrm{ng} / \mathrm{ml})$ was added to cultures activated with LPS/IFN- $\gamma$ and treated with IL-1 $\beta$, AA or prion protein/peptide and incubated for 15 minutes at $37^{\circ} \mathrm{C}$. Stained cells (microglia) were visualised and counted by viewing under a fluorescence microscope (excitation 488 $\mathrm{nm}$, emission $530 \mathrm{~nm}$ ).

\section{3-nitrotyrosine immunocytochemistry}

Mixed neuronal-glial cultures were stained for the peroxynitrite marker, 3-nitrotyrosine (3-NT). Cultures were untreated (control) or treated with LPS/IFN- $\gamma$, PMA, LPS/ IFN- $\gamma /$ PMA or FeTPPS + LPS/IFN- $\gamma /$ PMA. Cultures were fixed with $4 \%$ paraformaldehyde and then incubated with $10 \mu \mathrm{g} / \mathrm{ml}$ of anti-nitrotyrosine monoclonal antibody (Upstate). The primary antibody was detected using a Cy3-conjugated secondary antibody (Jackson ImmunoResearch Laboratories). 3-NT -positive cells were visualised using a fluorescence microscope (excitation $546 \mathrm{~nm}$, emission $590 \mathrm{~nm}$ ).

\section{Statistical analysis}

Data are expressed as mean \pm SEM and were analysed for significance using ANOVA.

\section{Results}

Inflammatory activation of glia in neuronal-glial cultures does not lead to substantial death of the co-cultured neurons

A mature mixed culture (16-18 days in vitro) of cerebellar granule neurons and glia (22\% astrocytes and $2 \%$ microglia) was used to investigate inflammation-activated gliainduced neuronal death. The glia in the neuronal-glial cultures were activated with a combination of endotoxin (lipopolysaccharide, LPS) and a pro-inflammatory cytokine (interferon- $\gamma$, IFN- $\gamma$ ) or different combinations of pro-inflammatory cytokines including tumour necrosis factor- $\alpha$ (TNF- $\alpha$ ) and interleukin-1 $\beta$ (IL-1 $\beta$ ). Neuronal death was assessed 48 hours after treatment with the inflammatory activators (LPS/IFN- $\gamma$, TNF- $\alpha /$ IFN- $\gamma$, IL- $1 \beta /$ IFN- $\gamma$ or TNF- $\alpha /$ IL- $1 \beta /$ IFN- $\gamma$ ). Two nuclear dyes were used to stain the cultures and assess for necrosis and apoptosis: cell-impermeable propidium iodide (PI) to stain necrotic cells and the cell-permeable Hoechst 33342 used to characterise any neuronal nuclei showing signs of chromatin condensation or nuclear fragmentation (characteristic of apoptosis). Although relatively small, significant levels of neuronal death were induced following activation with LPS/IFN- $\gamma$, TNF- $\alpha /$ IFN- $\gamma$ or TNF- $\alpha /$ IL- $1 \beta /$ IFN- $\gamma$ but not IL$1 \beta /$ IFN- $\gamma$ (Table 1$)$.

To confirm that the glia in the culture had actually been activated to express iNOS, we used a simple stain for nitric oxide synthase (NOS) activity (NADPH diaphorase staining) enabling us to visualise cells with NOS activity and distinguish between microglia and astrocytes based on morphology. Additionally we assessed nitrite levels in the culture medium as a measure of NO production (Table: 1). Non-activated cultures showed no NADPH diaphorase staining in glia, but low-level staining was seen in neurons (probably due to nNOS) and correlates with the low level of nitrite present in the medium (Figure: 1a; Table: 1 ). However, after treatment with LPS/IFN- $\gamma$, a high proportion of glia (both microglia and astrocytes) stained intensely for diaphorase activity (Figure: $1 \mathrm{~b}$ ). Treatment with TNF- $\alpha /$ IFN- $\gamma$, IL- $1 \beta /$ IFN- $\gamma$ or TNF- $\alpha /$ IL- $1 \beta /$ IFN- $\gamma$ resulted in much less diaphorase staining of glia, and little or no nitrite elevation, indicating a requirement for LPS to induce substantial iNOS expression.

Relatively pure neuronal cultures (CGC cultures isolated as described in the methods section and then treated with $10 \mu \mathrm{M}$ arabinoside cytosine at 18 hours to inhibit the proliferation of glia) consisting of $97 \pm 4 \%$ neurons, $2 \pm$ 

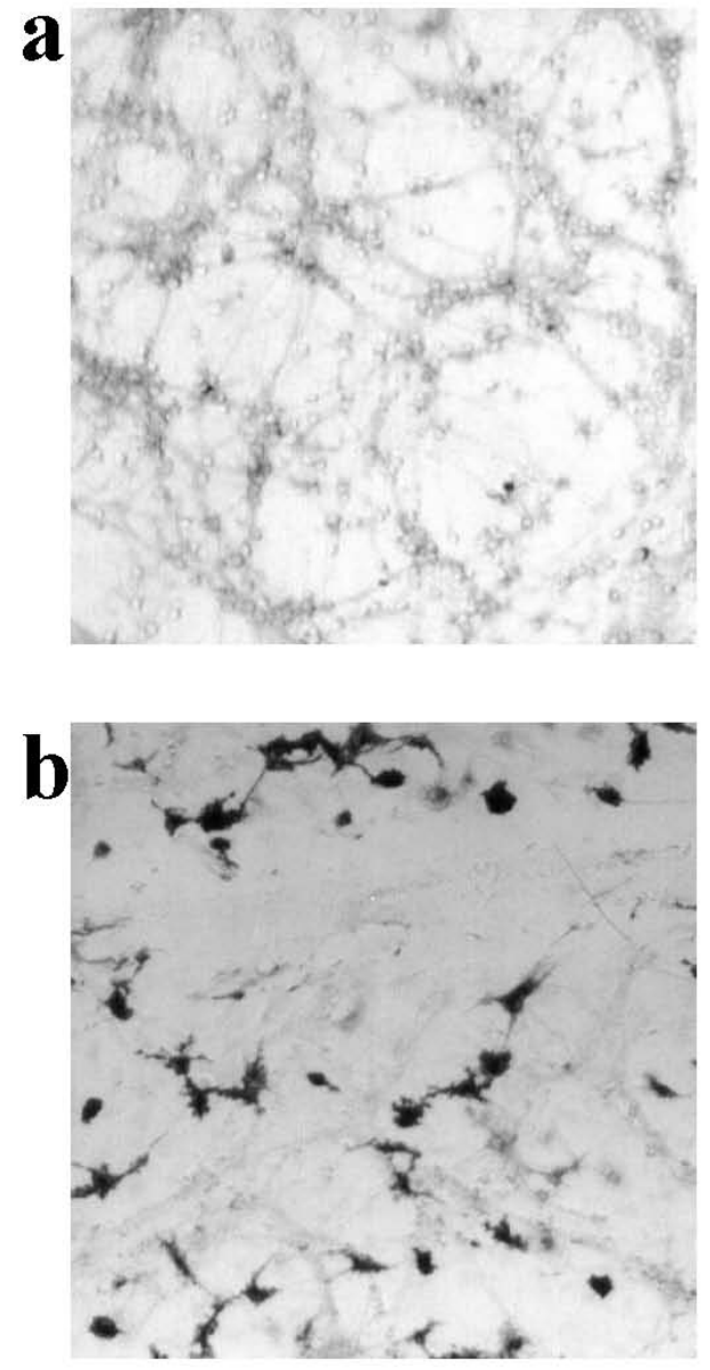

\section{Figure I}

NOS activity in mature neuronal-glial cultures. NADPH diaphorase staining was used to assess for NOS activity. Non-activated (control) cultures show weak staining in neurons and along their processes (a), but following LPS/ IFN- $\gamma$ treatment (b) dark staining is visible in glia (astrocytes and microglia). The photographs shown are representative and were taken 48 hours after treatment, $n>3$.

$1 \%$ astrocytes and $1 \pm 1 \%$ microglia were not affected by the presence of cytokines alone (mean \% of chromatincondensed (CC) and propidium iodide-positive (PI) neurons \pm SEM of 3 separate cultures; control: CC: $4 \pm 3 \%$, PI: $8 \pm 4 \% ; 10 \mathrm{ng} / \mathrm{ml} \mathrm{IL}-1 \beta:$ CC: $3 \pm 2 \%$, PI: $7 \pm 3 \% ; 10 \mathrm{ng} / \mathrm{ml}$
TNF- $\alpha$ : CC: $3 \pm 2 \%$, PI: $9 \pm 4 \%$ ). Additionally, no significant adverse effects were seen even if the concentrations of IL- $1 \beta$ or TNF- $\alpha$ were increased 10 -fold (mean $\%$ of neurons \pm SEM of 1 culture; control: CC: $4 \pm 3 \%$, PI: $8 \pm 4 \%$; $100 \mathrm{ng} / \mathrm{ml} \mathrm{IL-} 1 \beta$ : CC: $4 \pm 2 \%$, PI: $5 \pm 4 \% ; 100 \mathrm{ng} / \mathrm{ml} \mathrm{TNF}-$ $\alpha$ : CC: $4 \pm 2 \%$, PI: $6 \pm 4 \%$ ) or if combined with $10 \mathrm{ng} / \mathrm{ml}$ IFN- $\gamma$ treatment (mean \% of neurons \pm SEM of 2 separate cultures; control: CC: $4 \pm 3 \%$, PI: $8 \pm 4 \%$; $10 \mathrm{ng} / \mathrm{ml} \mathrm{IL-1} \beta$ + IFN- $\gamma$ : CC: $3 \pm 2 \%$, PI: $5 \pm 3 \% ; 10$ ng/ml TNF- $\alpha+$ IFN- $\gamma$ : CC: $3 \pm 3 \%$, PI: $7 \pm 2 \%$ ).

These results suggest that the cytokines have no direct toxicity for neurons, and although nitric oxide (NO) is produced by iNOS expressed in glia following activation with LPS/IFN- $\gamma$, it is not able to kill the co-cultured neurons alone, or the quantities of NO produced are not sufficient to induce widespread death of these mature neuronal cultures.

\section{Simultaneous activation of iNOS and NADPH oxidase results in massive neuronal death, mediated by peroxynitrite}

As NO produced by inflammatory activated glia did not induce substantial neuronal death, we investigated whether simultaneous production of superoxide resulting in peroxynitrite would be more toxic to neurons. Peroxynitrite is formed from the diffusion-limited reaction of $\mathrm{NO}$ with superoxide. Under inflammatory conditions in the brain, NADPH oxidase is the major source of superoxide, therefore we used phorbol 12-myristate 13-acetate (PMA) to activate this enzyme and generate a source of superoxide in the neuronal-glial culture. As the number of NADPH diaphorase-positive glia was greatest following treatment with LPS/IFN- $\gamma$, we used LPS/IFN- $\gamma$ to induce iNOS expression in the glia and provide a source of NO. We found that treating neuronal-glial cultures with LPS/ IFN- $\gamma /$ PMA for 48 hours induced extensive neuronal death (Figure: 2a). Treatment of the cultures with PMA alone induced only low levels of neuronal death, similar to that seen with LPS/IFN- $\gamma$ treatment alone. However, activation of both NADPH oxidase and iNOS was synergistic in inducing neuronal death. This neuronal death was prevented by an iNOS inhibitor of $(1400 \mathrm{~W})$, a NADPH oxidase (apocynin) a peroxynitrite scavenger (FeTPPS), but not by a blocker of the NMDA receptor (MK-801).

As PMA activates the protein kinase $C$ pathway, the effects of PMA might be due to reasons other than stimulating the microglial NADPH oxidase, such as increased iNOS expression leading to more NO production and neuronal death by NO and not peroxynitrite. However, the levels of nitrite and nitrate in the culture medium of neuronal-glial cultures treated with LPS/IFN- $\gamma /$ PMA were not different to those found in the absence of PMA (Figure: 2b). 

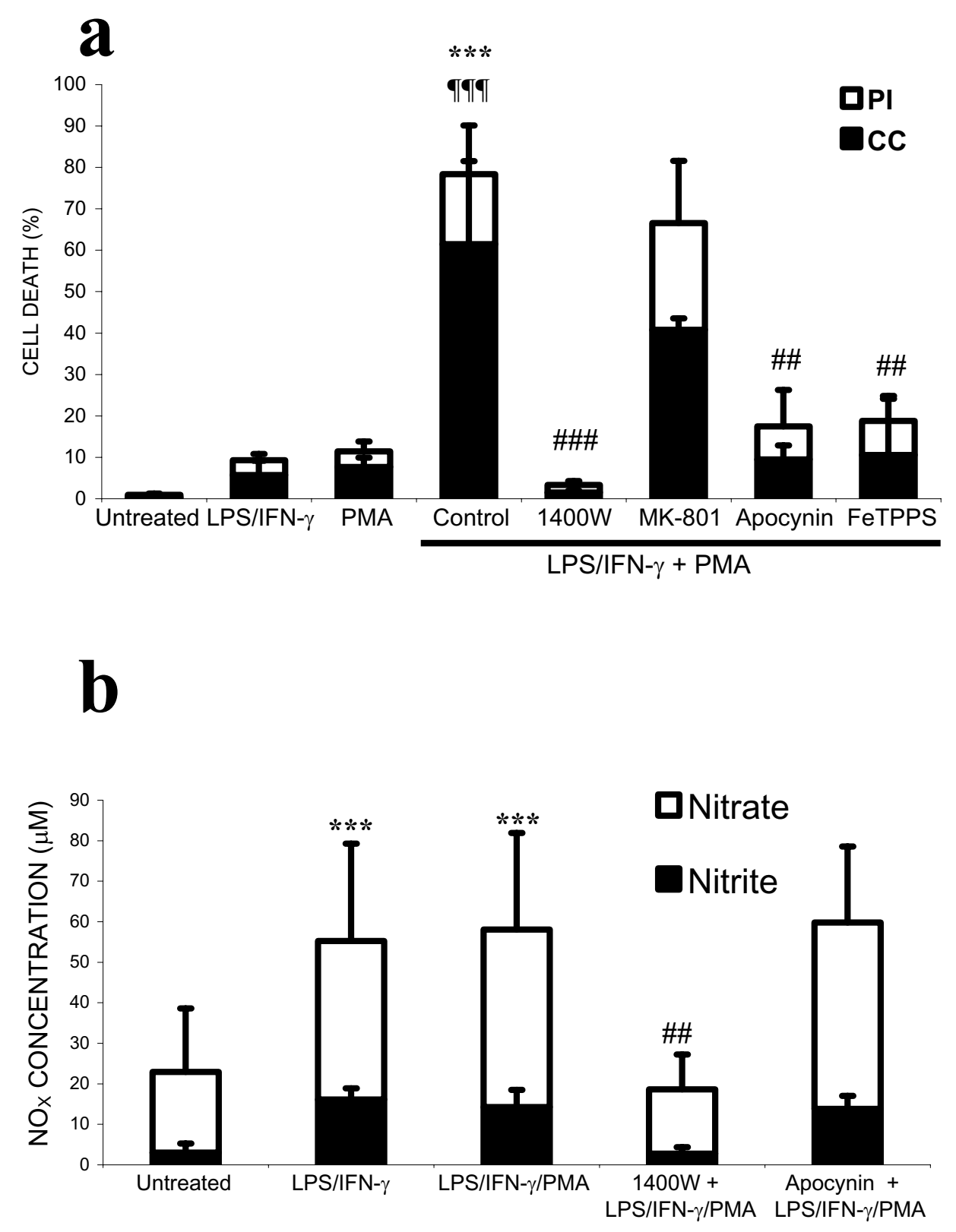

Figure 2

Activation of NADPH oxidase in the presence of glial iNOS is synergistic in killing co-cultured neurons. Cultures were stained with the cell-impermeable dye propidium iodide (PI) to count necrotic cells and the cell-permeable dye Hoechst 33342 to count neuronal nuclei showing chromatin condensation/fragmentation (CC), 48 hours after treatment (a). PMA stimulation of NADPH oxidase did not substantially affect neuronal survival, but in the presence of LPS/IFN- $\gamma$ had synergistic effects on neuronal death, which were blocked by inhibitors of iNOS (25 $\mu$ M I400W), NADPH oxidase (I mM apocynin), or a peroxynitrite scavenger (I00 $\mu$ M FeTPPS) but not by a blocker of the NMDA receptor (I0 $\mu$ M MK-80I). Nitrite and nitrate levels were not affected by the presence of PMA or apocynin but were significantly reduced by I400W (b). Statistical differences were established using ANOVA at $*_{p}<0.05$, $*_{p}<<0.01$ and $*_{* *} * 0.001$, the symbol \# replaces $*$ when comparing protection against LPS/IFN- $\gamma /$ PMA induced neuronal death. The symbol $\rceil$ is used to demonstrate a significant difference in comparison to PMA or LPS/IFN- $\gamma$ alone. Statistical significance refers to the total death (black + white parts of the bar). Data expressed is mean \pm SEM, $\mathrm{n}=3$ or more. 

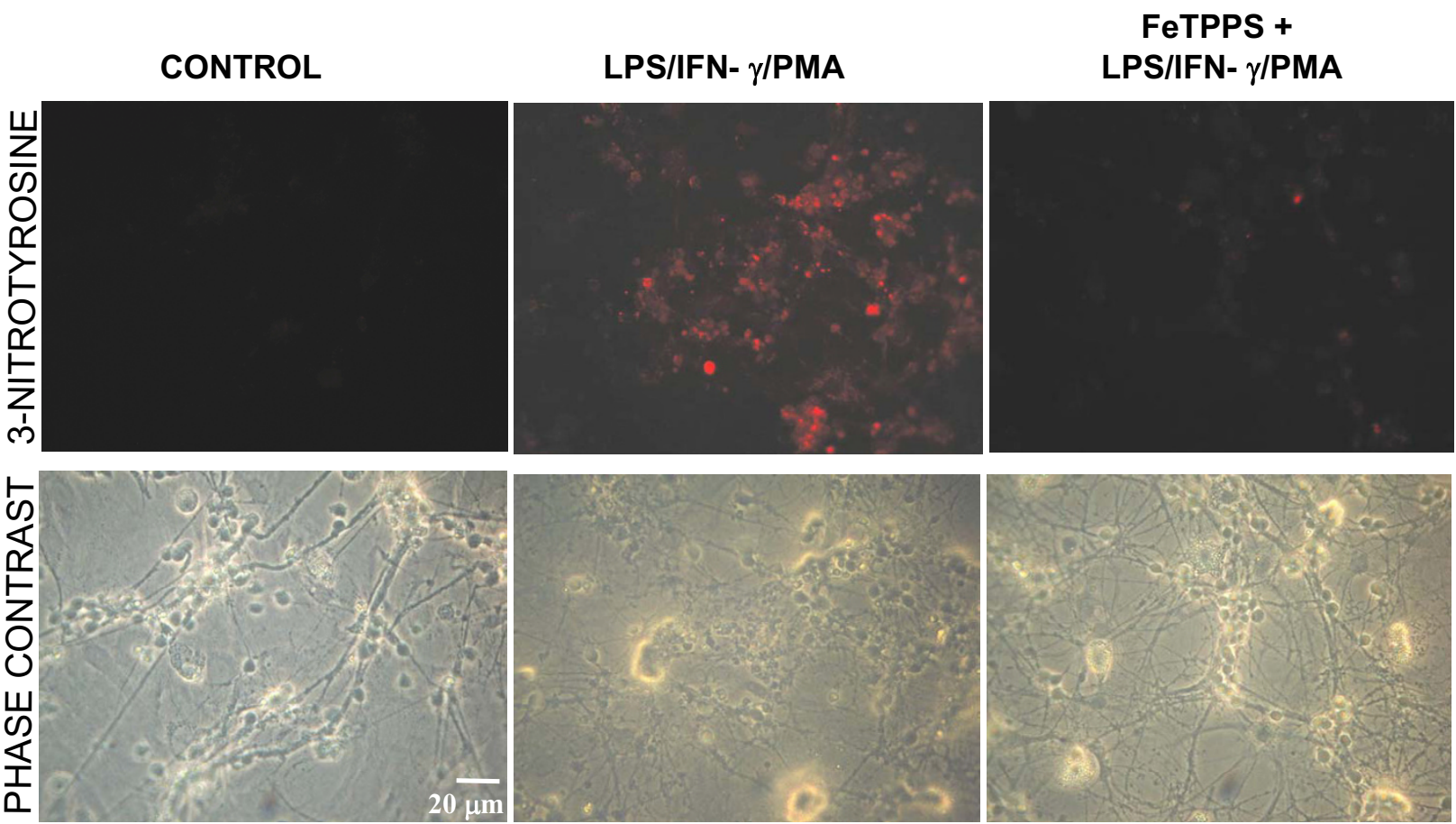

\section{Figure 3}

Activation of NADPH oxidase in the presence of iNOS expression leads to 3-nitrotyrosine immunoreactivity in neurons and glia. Neuronal-glial cultures treated with LPS/IFN- $\gamma / P M A$ for 48 hours showed extensive immunoreactivity for 3-nitrotyrosine, which was absent in the presence of FeTPPS. Untreated cultures (control) showed no staining for 3-nitrotyrosine. The photographs shown are representative and were taken 48 hours after treatment, $n>3$.

To determine whether peroxynitrite generated by glia reaches the neurons, the neuronal-glial cultures were tested for nitrotyrosine immunoreactivity. Positively stained neurons (and glia) were only seen following treatment with LPS/IFN- $\gamma /$ PMA (Figure: 3 ) and not in the presence of the peroxynitrite scavenger FeTPPS or when treated with LPS/IFN- $\gamma$ (data not shown) or PMA alone (data not shown). However, no PI-positive glia or changes in glial nuclear morphology were observed in any of the conditions, implying that although they were exposed to peroxynitrite it did not induce glial death.

ATP is known to be released by neurons and glia in a variety of conditions, and has been reported to activate the microglial NADPH oxidase via P2X7 receptors [26]. We found that ATP rapidly stimulated superoxide/hydrogen peroxide production by isolated microglia, which was sensitive to diphenyleneiodonium (DPI), an inhibitor of NADPH oxidase (ATP: $80 \pm 7$ picomoles $\mathrm{H}_{2} \mathrm{O}_{2}$ /minute/ 1 $\times 10^{5}$ microglia). However, ATP did not induce neuronal death alone, or in synergy with LPS/IFN- $\gamma$ treatment (data not shown), probably because it is rapidly hydrolysed in cell culture medium [35]. Therefore, we used a nonhydrolysable ATP analogue, 2'-3'-O-(4- benzoylbenzoyl)ATP (BzATP), known to be a specific P2X7 receptor agonist [36]. BzATP was also found to stimulate DPI-sensitive hydrogen peroxide production by isolated microglia, which was comparable to that produced by PMA (control: $12 \pm 3$; PMA: $204 \pm 50$; BzATP: $124 \pm 15$ picomoles $\mathrm{H}_{2} \mathrm{O}_{2} /$ minute $1 \times 10^{5}$ microglia). BzATP did not induce neuronal death alone but had synergistic effects on neuronal death in the presence iNOS expression (Figure: 4). LPS/IFN- $\gamma /$ BzATP induced neuronal death was blocked by inhibitors of iNOS, NADPH oxidase and a peroxynitrite scavenger, but not by the NMDA receptor blocker. 


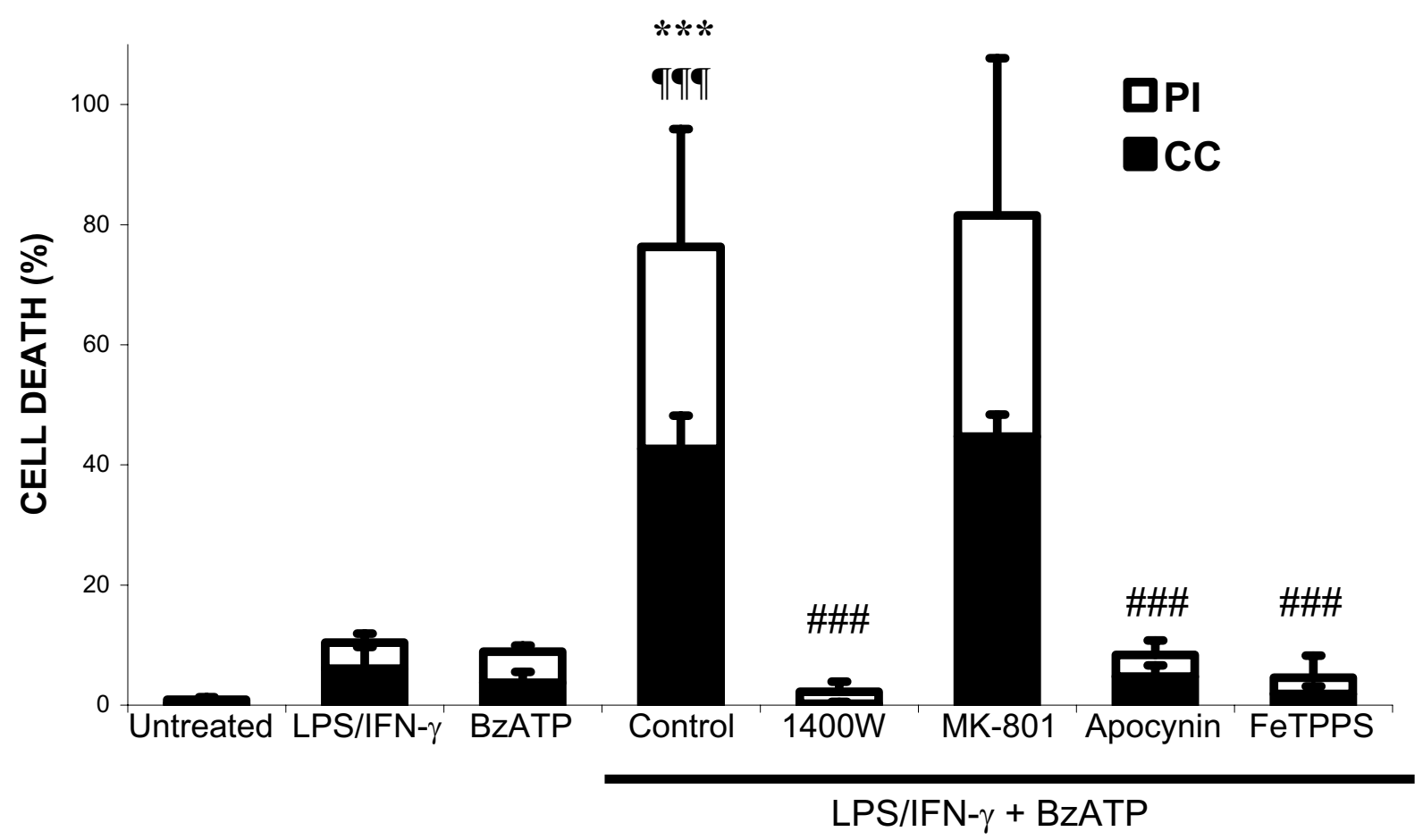

\section{Figure 4}

NADPH oxidase stimulation by $\mathbf{P} 2 X 7$ receptor activation in the presence of glial iNOS kills co-cultured neurons. Neuronal death was assessed by propidium iodide staining $(\mathrm{PI})$ and chromatin condensation of neuronal nuclei by Hoechst 33342 staining (CC) 48 hours after treatment. Neuronal death induced by BzATP following LPS/IFN- $\gamma$ activation, was prevented by inhibitors of iNOS $(25 \mu \mathrm{M}$ I400W), NADPH oxidase (I mM apocynin) and a peroxynitrite scavenger (I00 $\mu M$ FeTPPS) but not by a blocker of the NMDA receptor (I0 $\mu$ M MK-80I). Statistical differences were established using ANOVA at $*_{p}<0.05$ and $* * * p<0.001$, the symbol \# replaces * when comparing protection against LPS/IFN- $\gamma /$ BzATP induced neuronal death. Statistical significance refers to the total death (black + white parts of the bar). Data expressed is mean \pm SEM, $n=3$ or more.

\section{Activation of glia in microglia-enriched neuronal-glial cultures potently kills co-cultured neurons}

We have found that IL-1 $\beta$ or arachidonic acid (AA) can activate the microglial NADPH oxidase, although to lesser extent than PMA (control: $12 \pm 3$; IL-1 $\beta$ : $37 \pm 20$; AA: $24 \pm$ 4 picomoles $\mathrm{H}_{2} \mathrm{O}_{2} /$ minute $/ 1 \times 10^{5}$ microglia). We therefore tested whether IL- $1 \beta$ or AA could synergise with LPS/ IFN- $\gamma$ to induce neuronal death. The addition of either IL$1 \beta$ or AA did not induce further neuronal death than that induced by LPS/IFN- $\gamma$ alone up to 48 hours after additions (data not shown). However if such cultures were maintained for 6 days, we found that widespread neuronal death occurred (Figure: 5a, b) and was blocked by inhibitors of iNOS, NADPH oxidase, a peroxynitrite scavenger and a blocker of the NMDA receptor. Treatment with IL-
$1 \beta$ or AA alone did not have any effect on neuronal survival, but did increase the number of microglia in neuronal-glial cultures (Figure: 5c). Treatment with LPS/IFN- $\gamma$ was found to inhibit microglia proliferation but in the presence of IL- $1 \beta$ or AA this inhibition was overcome and lead to a progressive increase in the number of microglia and subsequent neuronal death. The mitogenic effects of IL-1 $\beta$ or AA are probably mediated by hydrogen peroxide following stimulation of NADPH oxidase (unpublished data) and we found that the NADPH oxidase inhibitor, apocynin, prevented this increase in the number of microglia. Nitrite and nitrate $\left(\mathrm{NO}_{\mathrm{X}}\right)$ levels (Figure: $5 \mathrm{~d}$ ) were higher in cultures treated with IL- $1 \beta$ or AA plus LPS/IFN$\gamma$, but not in the presence of apocynin, which blocked 

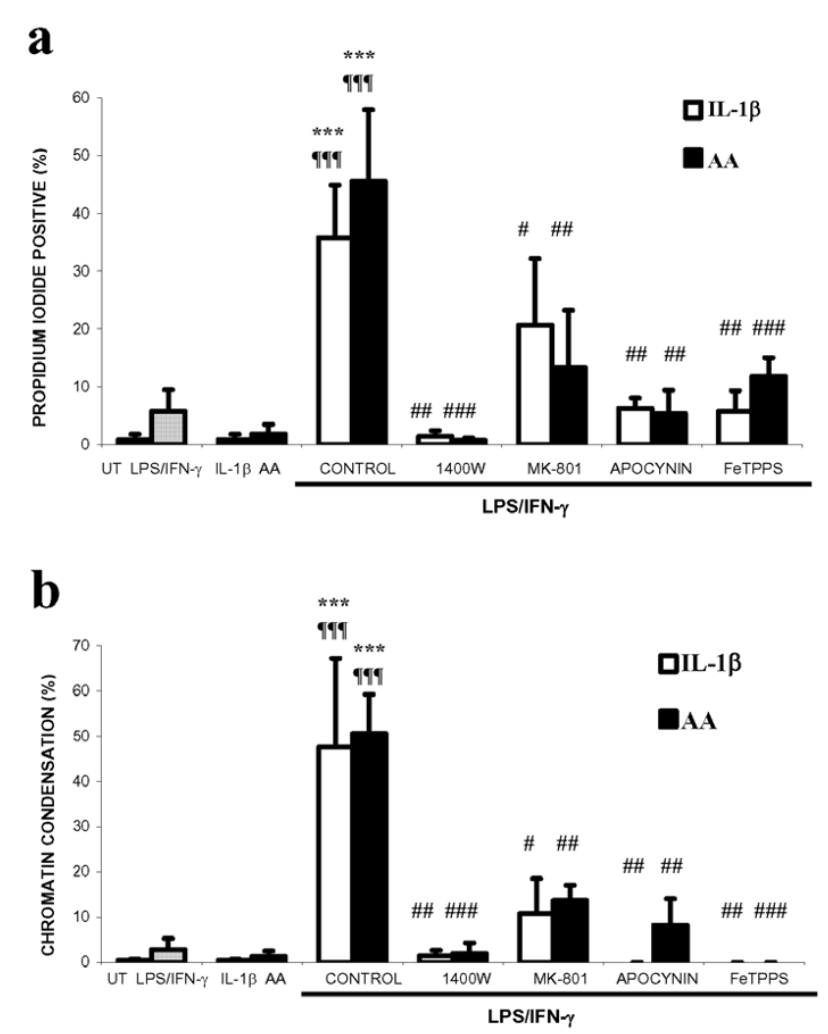
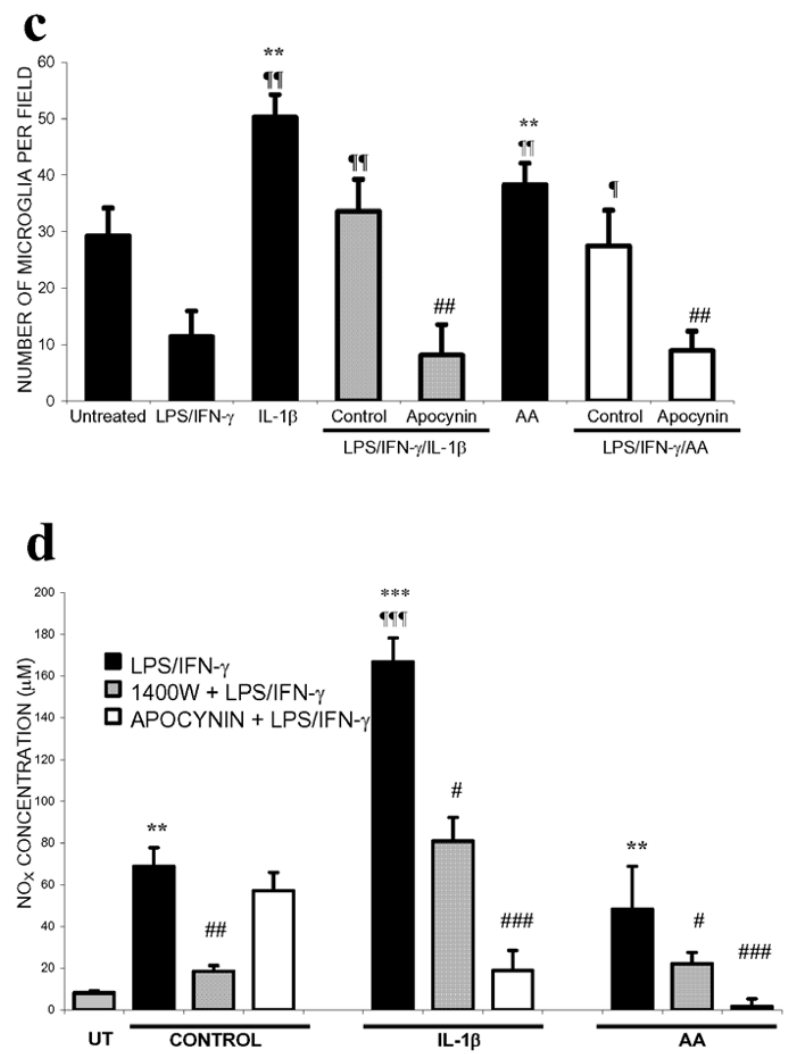

\section{Figure 5}

Effects of IL-I $\beta$ or arachidonic acid (AA) on neuronal survival in the presence of inflammation-activated glia in neuronal-glial cultures. Neuronal death was assessed by propidium iodide staining (PI; a) or chromatin condensation of neuronal nuclei (CC; b) after 6 days of treatment. Neuronal death was prevented by inhibitors of iNOS (25 $\mu M$ I400W), NADPH oxidase (I mM apocynin), a blocker of the NMDA-receptor (I0 $\mu$ M MK-80 I) or a peroxynitrite scavenger (I00 $\mu$ M FeTPPS). Neuronal death was accompanied by proliferation of microglia (c). Microglial proliferation was inhibited by LPS/IFN- $\gamma$ treatment alone but in the presence of IL-I $\beta$ or AA it was stimulated and returned to basal levels. This stimulation of proliferation by IL-I $\beta$ or AA (in the presence of LPS/IFN- $\gamma$ ) was completely prevented by apocynin. Additionally, nitrite/nitrate (NO $\mathrm{N}_{\mathrm{X}}$ ) levels correlated with the number of microglia present (d). Statistical differences were established using ANOVA at $* p<0.05$, $* * p<$ 0.01 and $* * * p<0.001$, the symbol $*$ is used when assessing prevention of neuronal death in comparison to LPS/IFN- $\gamma$ with ILI $\beta$ or AA. The symbol $\Phi$ is used when comparing neuronal death to that induced by LPS/IFN- $\gamma$ alone and \# when comparing neuronal death induced by IL-I $\beta$ or AA treatment alone. In $c \& d$, the differences are in comparison to IL-I $\beta$ or AA alone $(*)$, LPS/IFN- $\gamma$ (II) or LPS/IFN- $\gamma$ plus IL-I $\beta$ or AA (\#). Data expressed is mean \pm SEM, $\mathrm{n}=3$ or more.

microglial proliferation, suggesting that microglia were the predominant source of NO and/or peroxynitrite.

Since IL-1 $\beta$ and AA stimulated microglial proliferation (in the presence or absence of LPS/IFN- $\gamma$ ), we wanted to test whether increasing the microglial density would sensitise to LPS/IFN- $\gamma$ induced neuronal death. So we investigated whether enriching the microglia population in the neuronal-glial culture followed by inflammatory activation would result in widespread neuronal death. The neuronal-glial culture used in the last section was enriched with microglia by adding freshly isolated microglia. LPS/ IFN- $\gamma$ activation of a microglia-rich $(15 \%$ microglia as opposed to $2 \%$ ) neuronal-glial culture resulted in all neurons rapidly losing their dendritic processes and shrinkage of the cell body (Figure: 6b), in addition to chromatin condensation or propidium iodide staining of the nuclei at 48 hours of treatment (Figure: $6 a$ ). This neuronal death was prevented by inhibitors of iNOS, NADPH oxidase, a peroxynitrite decomposition catalyst and a blocker of the NMDA receptor. The addition of microglia alone (nonactivated) did not affect neuronal survival (Figure: 6a, 


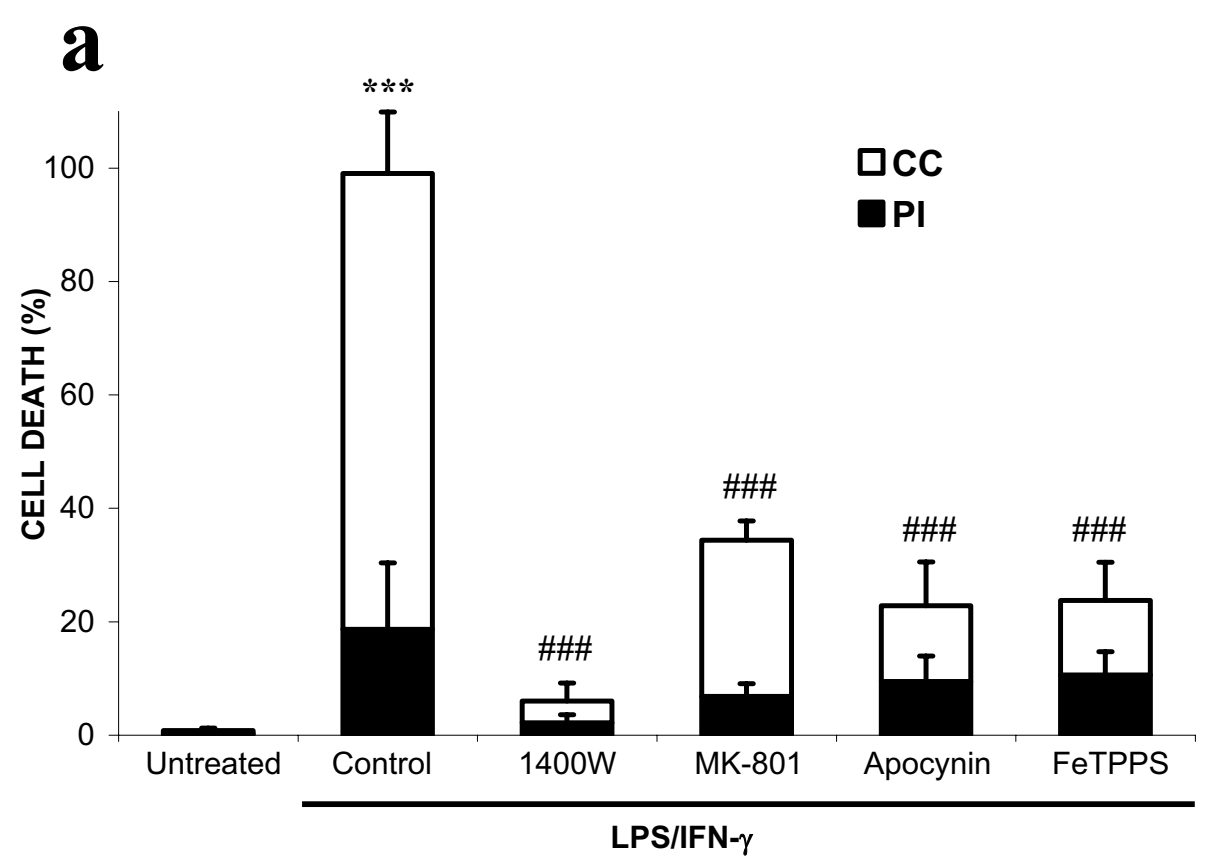

b

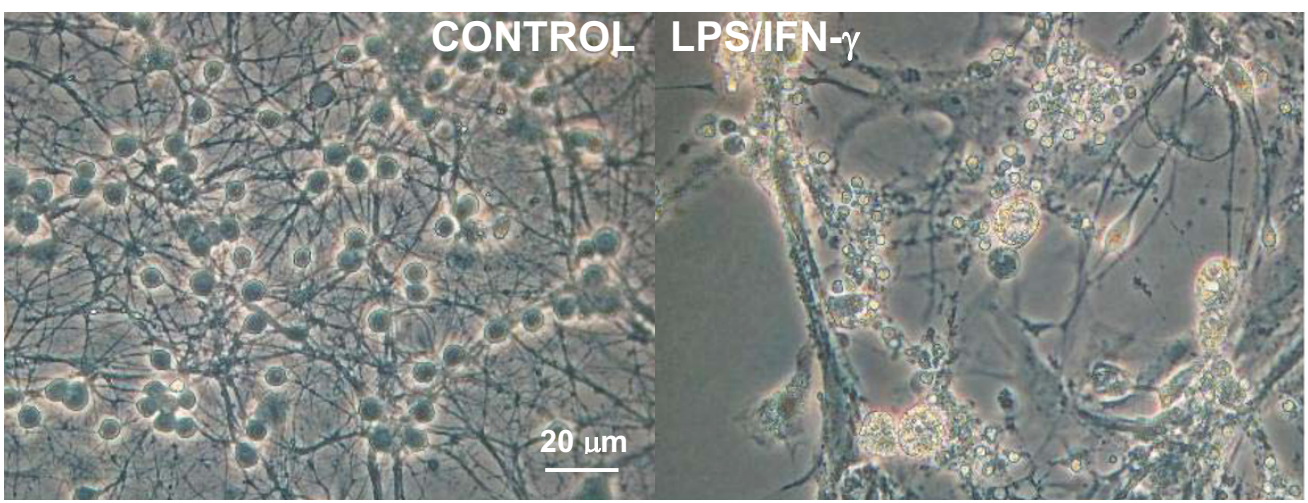

\section{Figure 6}

Activation of microglia-enriched neuronal-glial cultures induces complete neurodegeneration. The microglia population was enriched in neuronal-glial cultures by adding isolated microglia $\left(50,000 \mathrm{microglia} / \mathrm{cm}^{2}\right)$. Neuronal death was assessed by propidium iodide staining (PI) or chromatin condensation of neuronal nuclei (CC) at 48 hours after treatment (a). Neuronal death was prevented by inhibitors of iNOS ( $25 \mu \mathrm{M}$ I400W), NADPH oxidase (I mM apocynin), a blocker of the NMDA-receptor (I0 $\mu \mathrm{M}$ MK-80I), or a peroxynitrite scavenger (I00 $\mu$ M FeTPPS). LPS/IFN- $\gamma$ activation of the microgliaenriched neuronal-glial cultures led to complete disintegration of neuronal processes and severe shrinkage of neuronal cell bodies (b). Statistical differences were established using ANOVA at $*_{p}<0.05$ and $* * * p<0.001$, in comparison to control (added microglia) non-activated cultures, and the symbol \# replaces * when comparing protection against neuronal death induced by LPS/IFN- $\gamma$ activated cultures. Statistical significance refers to the total death (black + white parts of the bar). Data expressed is mean \pm SEM, $n=3$ or more. Photographs shown are representative and were taken 48 hours after the addition of LPS/IFN- $\gamma$. 
Table 2: Prion protein or peptide (PrP I06-126) does not affect neuronal survival. Neuronal-glial cultures treated once with either prion protein $(5 \mu \mathrm{g} / \mathrm{ml})$ or PrP I 06-1 $26(225 \mu \mathrm{g} / \mathrm{ml})$ did not induce neuronal death over a period of 7 days (assessed by Hoechst 33342 to visualise chromatin condensation (CC) or propidium iodide (PI) to stain necrotic cells). However, prion protein or PrP I06-I26 did stimulate the proliferation of microglia in neuronal-glial cultures over the same period of time. Statistical differences were established using ANOVA at $* p<0.05, * *<<0.01$ and $* * * p<0.001$ and are in comparison to untreated cultures (symbol $*$ ); data expressed is mean \pm SEM, $n=3$ or more.

\begin{tabular}{cccc}
\hline Treatment & PI (\%) & CC (\%) & Microglia per field \\
\hline Untreated & $2.0 \pm 1.6$ & $0.6 \pm 0.3$ & $22 \pm 5$ \\
Prion protein & $2.9 \pm 0.5$ & $0.7 \pm 0.6$ & $53 \pm 8$ *** \\
PrPI06-126 & $1.0 \pm 0.8$ & $0.7 \pm 0.4$ & $51 \pm 7$ ****
\end{tabular}

untreated). In support of microglia as the key cell type in inflammatory neurodegeneration, LPS/IFN- $\gamma$ activation of astrocyte-enriched neuronal-glial cultures did not lead to widespread killing of co-cultured neurons (isolation of neuronal-glial cultures as normal but plated onto a confluent bed of astrocytes; data not shown).

\section{Prion protein or PrP I06-I 26 induce neuronal death in the presence of inflammatory activation mediated by microglia and NADPH oxidase activation}

The prion peptide, PrP106-126, has previously been shown to activate microglia, causing proliferation and ROS production $[37,38]$. We have recently found that the prion protein and peptide stimulate the NADPH oxidase in isolated microglia (control: $12 \pm 3$; prion protein: $29 \pm$ 3; $\operatorname{PrP106-126:~} 38 \pm 13$ picomoles $\mathrm{H}_{2} \mathrm{O}_{2} /$ minute $/ 1 \times 10^{5}$ microglia). We decided to investigate whether the addition of PrP106-126 to iNOS-expressing glia in neuronalglial cultures would also lead to delayed neurodegeneration, mediated by peroxynitrite and microglia. The addition of prion protein or PrP106-126 alone did not affect neuronal survival in these mature neuronalglial cultures, but did lead to microglial proliferation (Table: 2). In the presence of glial iNOS (following LPS/ IFN- $\gamma$ treatment), PrP106-126 or prion protein did not exacerbate neuronal death over a period of 2 days, but were synergistic in killing the co-cultured neurons at 6 days (Figure: $7 \mathrm{a}, \mathrm{b}$ ), while a scrambled peptide of the PrP106-126 sequence had no effect. Neuronal death was prevented by blocking NO production from iNOS $(1400 \mathrm{~W})$, or superoxide from NADPH oxidase (apocynin), through the removal of peroxynitrite (FeTPPS), or by inhibiting the NMDA receptor (MK-801). Additionally, neuronal death was accompanied by microglia proliferation, which was blocked by apocynin (Figure: $7 \mathrm{c}$ ). Nitrite/nitrate levels were also suppressed in the presence of apocynin, as well as 1400W (Figure: 7d).

\section{Discussion}

We found that LPS/IFN- $\gamma$ induced NOS activity within cultured glia, but induced relatively little death of co-cultured neurons. It has previously been reported that LPS/ cytokine-induced iNOS expression in glia is sufficient $[5,8,39,40]$ or insufficient [41-43] to induce death of cocultured neurons. Similarly, in vivo it has been reported that iNOS expression is sufficient $[44,45]$ or insufficient [46-48] to induce neuronal death. This suggests that either there is a threshold level for $\mathrm{NO} / \mathrm{iNOS}$ induced neuronal death [49], or NO/iNOS-induced neuronal death is conditional upon some other factors. We have recently reported one such conditional factor (hypoxia) that synergises with $\mathrm{NO} / \mathrm{iNOS}$ to induce neuronal death [31]. In this report we have tested the hypothesis that $\mathrm{NO} / \mathrm{iNOS}$ induced neuronal death is conditional upon microglial NADPH oxidase activation.

It has previously been shown that PMA stimulation of microglia results in superoxide production through stimulation of NADPH oxidase [50] and, in the presence of LPS/IFN- $\gamma$ activated glia (producing NO from iNOS), the superoxide combines with NO to form peroxynitrite [32]. We found that if the NADPH oxidase was stimulated by PMA in the presence of LPS/IFN- $\gamma$ activated glia, it resulted in extensive death of the co-cultured neurons, while PMA alone induced very little neuronal death. In pathophysiological conditions, extracellular levels of ATP can increase [51], and ATP can activate purinergic receptors (more specifically P2X7 receptors), which can lead to the activation of NADPH oxidase [26]. We used a specific P2X7 receptor agonist (BzATP) to activate the NADPH oxidase in the presence of iNOS expression (LPS/IFN- $\gamma$ activated cultures) and we found extensive neuronal death, comparable to that induced by LPS/IFN- $\gamma /$ PMA. Neuronal-glial cultures activated with LPS/IFN- $\gamma /$ PMA or LPS/IFN- $\gamma$ / BzATP induced delayed neuronal death that occurred over 2 days. This is partly due to the time taken for iNOS expression, but it also implies that once peroxynitrite is generated neuronal death is not immediate.

In both cases (LPS/IFN- $\gamma /$ PMA or LPS/IFN- $\gamma /$ BzATP), inhibitors of iNOS or NADPH oxidase or a scavenger of peroxynitrite prevented this neuronal death, implicating 

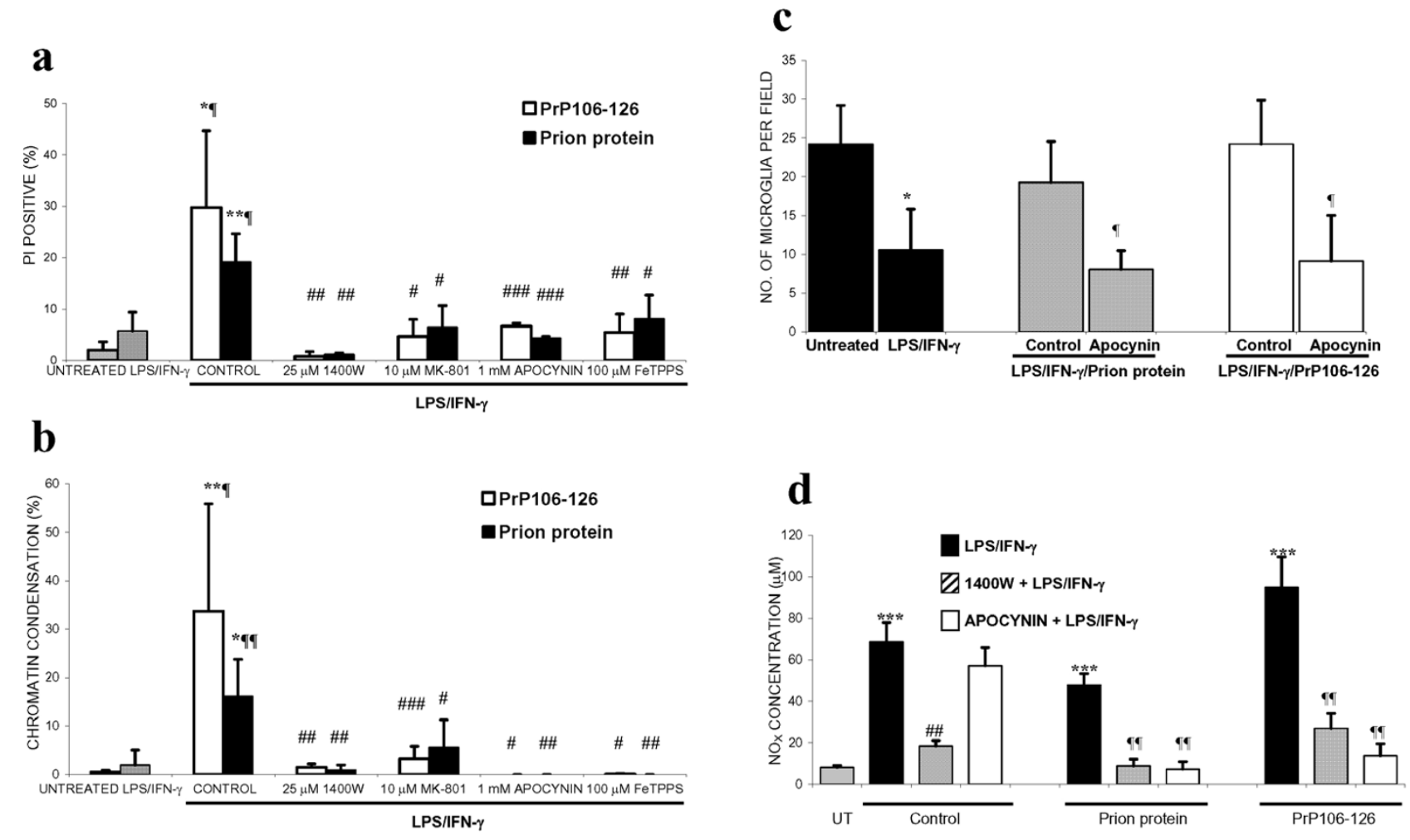

Figure 7

Delayed neurodegeneration induced by prion protein or PrP I06-I 26 in the presence of iNOS expression is microglia-dependent and mediated by peroxynitrite. The addition of prion protein $(5 \mu \mathrm{g} / \mathrm{ml})$ or PrPI06-I26 (225 $\mu \mathrm{g} /$ $\mathrm{ml}$ ) to LPS/IFN- $\gamma$ treated neuronal-glial cultures induced delayed death of co-cultured neurons, over 6 days. Neuronal death, assessed by Hoechst 33342 to visualise chromatin condensation (CC; b) or PI for necrosis (a) was prevented by inhibitors of iNOS (25 $\mu \mathrm{M} \mathrm{I}$ I400W) and NADPH oxidase (I mM apocynin), a peroxynitrite scavenger (I00 $\mu$ M FeTPPS) or a blocker of the NMDA receptor (I0 $\mu$ M MK-80I). Neuronal death was accompanied by proliferation of microglia (c). Microglial proliferation was inhibited by LPS/IFN- $\gamma$ treatment alone but in the presence of prion protein or PrPI06-I26 it was stimulated and returned to basal levels. This stimulation of proliferation by prion protein or PrPI06-I26 (in the presence of LPS/IFN- $\gamma$ ) was completely prevented by apocynin. Additionally, nitrite/nitrate $\left(\mathrm{NO}_{x}\right)$ levels correlated with the number of microglia present (d). Statistical differences were established using ANOVA at $*_{p}<0.05$, $* *_{p}<0.01$ and $*_{*} * p<0.001$ are in comparison to untreated cultures (symbol *) or LPS/IFN- $\gamma$ treatment (symbol T) or LPS/IFN- $\gamma$ plus prion protein or PrPI06-I26 (symbol \#); data expressed is mean \pm SEM, $n=3$ or more. In c \& d, the differences are in comparison to prion protein or PrPI06-I26 alone (*), LPS/IFN- $\gamma$ (II) or LPS/IFN- $\gamma$ plus prion protein or PrPI06-I26 (\#). Data expressed is mean \pm SEM, $n=3$ or more.

peroxynitrite as the potential mediator of neuronal death and the source of peroxynitrite as NO from iNOS and superoxide from NADPH oxidase. The putative peroxynitrite marker nitrotyrosine, was found in both neurons and some glia, implying that LPS/IFN- $\gamma /$ PMA treatment does result in peroxynitrite production that reacts with neurons. Furthermore, the peroxynitrite decomposition catalyst prevents the occurrence of nitrotyrosine-positive neurons following LPS/IFN- $\gamma /$ PMA treat- ment. FeTPPS has been shown to rapidly react and catalyse the decomposition of extracellular peroxynitrite [52] and inhibit tyrosine nitration [53]. The presence of nitrotyrosine immunoreactivity in glia did not appear to induce glial death. It has been found that glia can up-regulate their antioxidant defences to become more resistant to oxidative stress [54], which may explain the lack of change in glial morphology. 
The mechanism of peroxynitrite-induced neuronal death is still unclear but has been proposed to involve DNAdamage induced PARP activation [55], damage to the mitochondrial respiratory chain [56], and lipid peroxidation [57]. It is still controversial whether peroxynitriteinduced neuronal death involves activation of the NMDA receptor $[58,59]$. We found that a blocker of the NMDAreceptor did not prevent the relatively acute neuronal death induced by LPS/IFN- $\gamma /$ PMA or LPS/IFN- $\gamma /$ BzATP, but did prevent the relatively slow neuronal death induced by LPS/IFN- $\gamma / \mathrm{IL}-1 \beta$ or LPS/IFN- $\gamma / \mathrm{AA}$, although in both cases death was prevented by a peroxynitrite decomposer. It is possible that low, sustained levels of peroxynitrite induce neuronal death via the NMDA receptor, whereas high, acute levels induce death by other means, but we have not directly tested this. We found that IL-1 $\beta$ or AA activated NADPH oxidase hydrogen peroxide production to a lesser extent than PMA but, like PMA, either IL-1 $\beta$ or AA synergised with LPS/IFN- $\gamma$ to induce neuronal death mediated by peroxynitrite following activation of iNOS and NADPH oxidase. However the neuronal death induced by LPS/IFN- $\gamma /$ IL- $1 \beta$ or LPS/IFN- $\gamma /$ AA occurred over 6 days, rather than 2 days as with LPS/IFN$\gamma /$ PMA or LPS/IFN- $\gamma /$ BzATP. This relative delay might be due to the lower level of NADPH oxidase activation and thus peroxynitrite production. Additionally, Il- $1 \beta$ or AA caused microglial proliferation during the 6-day cultures, which may have contributed to the delayed neuronal death. Recently we found that IL-1 $\beta$ or AA stimulated microglial proliferation in microglia-astrocyte cultures via hydrogen peroxide production from NADPH oxidase (manuscript in preparation). Here we have shown that IL$1 \beta$ or AA stimulate the proliferation of microglia in neuronal-glial cultures, even in the presence of LPS/IFN- $\gamma$ (which itself inhibits microglial proliferation). In order to test whether an increase in microglia would potentiate LPS/IFN- $\gamma$ induced neuronal death, we added extra isolated microglia to the neuronal-glial culture, increasing the microglial population from $2 \%$ to $15 \%$ of cells in the co-culture. In such microglia-enriched cultures, LPS/IFN- $\gamma$ induced neuronal death was greatly increased. These observations suggest that microglia are essential for inflammatory activated glia-induced neuronal death, and one reason for this may be the expression of NADPH oxidase, which is predominantly localised to microglia [24].

Transmissible spongiform encephalopathies (Prion diseases) are lethal neurodegenerative disorders characterised by the progressive accumulation of a protease resistant isoform (PrPsc) of the normal host prion protein $(\mathrm{PrPc})$, in amyloid plaques [60]. An inflammatory response, predominantly mediated by microglia, is seen in post-mortem brain tissue, in transgenic models of the disease, and in culture [61]. A peptide, consisting of residues 106-126 (PrP106-126) of the human prion protein, replicates many of the pathological mechanisms involved in prion diseases and provides a good in vitro model. Contrary to published data $[38,62]$, we observed no neurotoxicity following the addition of PrP106-126 alone to this mature neuronal-glial culture. We found that both prion protein and PrP106-126, but not a scrambled peptide, stimulated microglial proliferation when added to neuronal-glial cultures, and this proliferation was blocked by a NADPH oxidase inhibitor. Both prion protein and peptide were synergistic in killing neurons in the presence of glial iNOS, in a peroxynitrite and microglia-dependent mechanism. The addition of the cellular isoform of prion protein to cell cultures has previously been shown to have no toxic effects [34]. However, in the presence of glial iNOS we found it to induce significant levels of neuronal death, although significantly less than that induced by PrP106-126.

\section{Conclusion}

We have shown that in a mature mixed culture of neurons and glia, activation of iNOS or NADPH oxidase alone does not result in substantial neuronal death, but that simultaneous activation of both is synergistic in killing cocultured neurons. This neuronal death appears to be dependent on microglia, and microglial proliferation is itself stimulated by activating the NADPH oxidase. These results suggest a dual-key hypothesis for inflammatory neurodegeneration; i.e. that activation of glial iNOS or NADPH oxidase alone may be relatively benign, but when activated together they cause peroxynitrite-mediated neuronal death. The conditionality of $\mathrm{NO} / \mathrm{iNOS}$-induced neuronal death provides insight into the mechanisms of inflammatory neurodegeneration and suggests that microglial NADPH oxidase may be a key therapeutic target.

\section{Competing interests}

The author(s) declare that they have no competing interests.

\section{Authors' contributions}

PM participated in the design of this study, did the lab work, data analysis and wrote major parts of the paper. GCB conceived the study, participated in its design and helped to draft the manuscript. Both authors read and approved the final manuscript.

\section{Acknowledgements}

This work was supported by the BBSRC, MRC and Alzheimer's Research Trust.

\section{References}

I. Eddleston M, Mucke L: Molecular profile of reactive astrocytes-implications for their role in neurologic disease. Neuroscience 1993, 54:|15-36.

2. Kreutzberg GW: Microglia: a sensor for pathological events in the CNS. Trends Neurosci 1996, 19:312-318. 
3. Polazzi E, Contestabile A: Reciprocal interactions between microglia and neurons: from survival to neuropathology. Rev Neurosci 2002, 13:221-242.

4. Banati RB, Gehrmann J, Schubert P, Kreutzberg GW: Cytotoxicity of microglia. Glia 1993, 7: III-II8.

5. Boje KM, Arora PK: Microglial-produced nitric oxide and reactive nitrogen oxides mediate neuronal cell death. Brain Res 1992, 587:250-256.

6. Brown GC, Bal-Price A: Inflammatory neurodegeneration mediated by nitric oxide, glutamate, and mitochondria. Mol Neurobiol 2003, 27:325-355.

7. McGeer PL, McGeer EG: The inflammatory response system of brain: implications for therapy of Alzheimer and other neurodegenerative diseases. Brain Res Brain Res Rev 1995, 21:195-218.

8. Bal-Price A, Brown GC: Inflammatory neurodegeneration mediated by nitric oxide from activated glia-inhibiting neuronal respiration, causing glutamate release and excitotoxicity. J Neurosci 200I, 21:6480-649I.

9. Chao CC, Hu S, Sheng WS, Bu D, Bukrinsky MI, Peterson PK: Cytokine-stimulated astrocytes damage human neurons via a nitric oxide mechanism. Glia 1996, 16:276-284.

10. Beckman JS, Chen J, Crow JP, Ye YZ: Reactions of nitric oxide, superoxide and peroxynitrite with superoxide dismutase in neurodegeneration. Prog Brain Res 1994, I03:37I-380.

II. Chao CC, Hu S, Peterson PK: Modulation of human microglial cell superoxide production by cytokines. J Leukoc Biol 1995, 58:65-70.

12. Bolanos JP, Almeida A, Stewart V, Peuchen S, Land JM, Clark JB, Heales SJ: Nitric oxide-mediated mitochondrial damage in the brain: mechanisms and implications for neurodegenerative diseases. J Neurochem 1997, 68:2227-2240.

13. Barger SW, Basile AS: Activation of microglia by secreted amyloid precursor protein evokes release of glutamate by cystine exchange and attenuates synaptic function. J Neurochem 200I, 76:846-854.

14. Chao CC, Hu S, Ehrlich L, Peterson PK: Interleukin-I and tumor necrosis factor-alpha synergistically mediate neurotoxicity: involvement of nitric oxide and of N-methyl-D-aspartate receptors. Brain Behav Immun 1995, 9:355-365.

15. Floyd RA: Antioxidants, oxidative stress, and degenerative neurological disorders. Proc Soc Exp Biol Med 1999, 222:236-245.

16. Metodiewa D, Koska C: Reactive oxygen species and reactive nitrogen species: relevance to cyto(neuro)toxic events and neurologic disorders. An overview. Neurotox Res 2000 I: $197-233$.

17. Zekry D, Epperson TK, Krause KH: A role for NOX NADPH oxidases in Alzheimer's disease and other types of dementia? IUBMB Life 2003, 55:307-3।3.

18. Shimohama S, Tanino $\mathrm{H}$, Kawakami N, Okamura N, Kodama $\mathrm{H}$, Yamaguchi T, Hayakawa T, Nunomura A, Chiba S, Perry G, Smith MA, Fujimoto S: Activation of NADPH oxidase in Alzheimer's disease brains. Biochem Biophys Res Commun 2000, 273:5-9.

19. Boven LA, Gomes L, Hery C, Gray F, Verhoef J, Portegies P, Tardieu $M$, Nottet HS: Increased peroxynitrite activity in AIDS dementia complex: implications for the neuropathogenesis of HIV-I infection. J Immunol 1999, 162:4319-4327.

20. Qin L, Liu Y, Wang T, Wei SJ, Block ML, Wilson B, Liu B, Hong JS: NADPH oxidase mediates lipopolysaccharide-induced neurotoxicity and proinflammatory gene expression in activated microglia. J Biol Chem 2004, 279:14| 5-|42I.

21. Green SP, Cairns B, Rae J, Errett-Baroncini C, Hongo JA, Erickson RW, Curnutte JT: Induction of gp9 I-phox, a component of the phagocyte NADPH oxidase, in microglial cells during central nervous system inflammation. J Cereb Blood Flow Metab 200I, 21:374-384.

22. Sastre J, Pallardo FV, Vina J: The role of mitochondrial oxidative stress in aging. Free Radic Biol Med 2003, 35: I-8.

23. Dugan LL, Sensi SL, Canzoniero LM, Handran SD, Rothman SM, Lin TS, Goldberg MP, Choi DW: Mitochondrial production of reactive oxygen species in cortical neurons following exposure to N-methyl-D-aspartate. J Neurosci 1995, 15:6377-6388.

24. Klegeris A, McGeer PL: Rat brain microglia and peritoneal macrophages show similar responses to respiratory burst stimulants. J Neuroimmunol I994, 53:83-90.
25. Benna JE, Dang PM, Gaudry M, Fay M, Morel F, Hakim J, GougerotPocidalo MA: Phosphorylation of the respiratory burst oxidase subunit p67(phox) during human neutrophil activation. Regulation by protein kinase $C$-dependent and independent pathways. J Biol Chem 1997, 272: 17204-17208.

26. Parvathenani LK, Tertyshnikova S, Greco CR, Roberts SB, Robertson $B$, Posmantur R: P2X7 mediates superoxide production in primary microglia and is up-regulated in a transgenic mouse model of Alzheimer's disease. J Biol Chem 2003, 278:13309-133|7.

27. Shiose A, Sumimoto $\mathrm{H}$ : Arachidonic acid and phosphorylation synergistically induce a conformational change of p47phox to activate the phagocyte NADPH oxidase. J Biol Chem 2000, 275: I3793-I380I.

28. Babior BM: NADPH oxidase. Curr Opin Immunol 2004, 16:42-47.

29. Murphy S, Simmons ML, Agullo L, Garcia A, Feinstein DL, Galea E, Reis DJ, Minc-Golomb D, Schwartz JP: Synthesis of nitric oxide in CNS glial cells. Trends Neurosci 1993, 16:323-328.

30. Bonfoco E, Krainc D, Ankarcrona M, Nicotera P, Lipton SA: Apoptosis and necrosis: two distinct events induced, respectively, by mild and intense insults with $\mathbf{N}$-methyl-D-aspartate or nitric oxide/superoxide in cortical cell cultures. Proc Natl Acad Sci U S A 1995, 92:7162-7166.

31. Mander P, Borutaite V, Moncada S, Brown GC: Nitric oxide from inflammatory-activated glia synergizes with hypoxia to induce neuronal death. J Neurosci Res 2005, 79:208-2 I5.

32. Bal-Price A, Matthias A, Brown GC: Stimulation of the NADPH oxidase in activated rat microglia removes nitric oxide but induces peroxynitrite production. I Neurochem 2002, 80:73-80.

33. Beckman JS, Crow JP: Pathological implications of nitric oxide, superoxide and peroxynitrite formation. Biochem Soc Trans 1993, 2 1:330-334.

34. Brown DR, Wong BS, Hafiz F, Clive C, Haswell SJ, Jones IM: Normal prion protein has an activity like that of superoxide dismutase. Biochem J 1999, 344 Pt I: I-5.

35. Mietkiewski K, Domka F, Malendowicz L, Malendowicz J: Studies on ATP hydrolysis in medium for histochemical demonstration of ATPase activity. Histochemie 1970, 24:343-353.

36. Michel AD, Xing M, Humphrey PP: Serum constituents can affect 2'-\& 3'-O-(4-benzoylbenzoyl)-ATP potency at $\mathbf{P 2 X ( 7 )}$ receptors. Br J Pharmacol 200I, I32:150I-I508.

37. Brown DR, Schmidt B, Kretzschmar HA: A neurotoxic prion protein fragment enhances proliferation of microglia but not astrocytes in culture. Glia 1996, 18:59-67.

38. Brown DR, Schmidt B, Kretzschmar HA: Role of microglia and host prion protein in neurotoxicity of a prion protein fragment. Nature 1996, 380:345-347.

39. Chao CC. Hu S, Molitor TW, Shaskan EG, Peterson PK: Activated microglia mediate neuronal cell injury via a nitric oxide mechanism. J Immunol 1992, 149:2736-274I.

40. Dawson VL, Brahmbhatt HP, Mong JA, Dawson TM: Expression of inducible nitric oxide synthase causes delayed neurotoxicity in primary mixed neuronal-glial cortical cultures. Neuropharmacology 1994, 33: 1425- I430.

41. Demerle-Pallardy C, Lonchampt MO, Chabrier PE, Braquet P: Nitric oxide synthase induction in glial cells: effect on neuronal survival. Life Sci 1993, 52:1883-1890.

42. Hewett SJ, Csernansky CA, Choi DW: Selective potentiation of NMDA-induced neuronal injury following induction of astrocytic iNOS. Neuron 1994, 13:487-494.

43. Stone R, Stewart VC, Hurst RD, Clark JB, Heales SJ: Astrocyte nitric oxide causes neuronal mitochondrial damage, but antioxidant release limits neuronal cell death. Ann N Y Acad Sci 1999, 893:400-403

44. Iravani MM, Kashefi K, Mander P, Rose S, Jenner P: Involvement of inducible nitric oxide synthase in inflammation-induced dopaminergic neurodegeneration. Neuroscience 2002 I I 0:49-58.

45. Ding M, Zhang M, Wong JL, Rogers NE, Ignarro LJ, Voskuhl RR: Antisense knockdown of inducible nitric oxide synthase inhibits induction of experimental autoimmune encephalomyelitis in SJL/J mice. J Immunol 1998, 160:2560-2564.

46. David JP, Ghozali F, Fallet-Bianco C, Wattez A, Delaine S, Boniface B, Di Menza C, Delacourte A: Glial reaction in the hippocampal formation is highly correlated with aging in human brain. Neurosci Lett 1997, 235:53-56. 
47. Ma SX, Holley AT, Sandra A, Cassell MD, Abboud FM: Increased expression of nitric oxide synthase in the gracile nucleus of aged rats. Neuroscience 1997, 76:659-663.

48. Vernet D, Bonavera JJ, Swerdloff RS, Gonzalez-Cadavid NF, Wang C: Spontaneous expression of inducible nitric oxide synthase in the hypothalamus and other brain regions of aging rats. Endocrinology 1998, 139:3254-326I.

49. Golde S, Chandran S, Brown GC, Compston A: Different pathways for iNOS-mediated toxicity in vitro dependent on neuronal maturation and NMDA receptor expression. I Neurochem 2002, 82:269-282.

50. Sumimoto $H$, Kage $Y$, Nunoi $H$, Sasaki $H$, Nose T, Fukumaki $Y$, Ohno M, Minakami S, Takeshige K: Role of Src homology 3 domains in assembly and activation of the phagocyte NADPH oxidase. Proc Natl Acad Sci U S A 1994, 91:5345-5349.

51. Le Feuvre R, Brough D, Rothwell N: Extracellular ATP and P2X7 receptors in neurodegeneration. Eur J Pharmacol 2002, 447:26I-269.

52. Crow JP: Manganese and iron porphyrins catalyze peroxynitrite decomposition and simultaneously increase nitration and oxidant yield: implications for their use as peroxynitrite scavengers in vivo. Arch Biochem Biophys 1999, 37 I:4I-52.

53. Misko TP, Highkin MK, Veenhuizen AW, Manning PT, Stern MK, Currie MG, Salvemini D: Characterization of the cytoprotective action of peroxynitrite decomposition catalysts. J Biol Chem 1998, 273: I 5646-I5653.

54. Acarin L, Peluffo H, Barbeito L, Castellano B, Gonzalez B: Astroglial nitration after postnatal excitotoxic damage: correlation with nitric oxide sources, cytoskeletal, apoptotic and antioxidant proteins. J Neurotrauma 2005, 22: 189-200.

55. Nguyen T, Brunson D, Crespi CL, Penman BW, Wishnok JS, Tannenbaum SR: DNA damage and mutation in human cells exposed to nitric oxide in vitro. Proc Natl Acad Sci U S A 1992, 89:3030-3034.

56. Bolanos JP, Heales SJ, Land JM, Clark JB: Effect of peroxynitrite on the mitochondrial respiratory chain: differential susceptibility of neurones and astrocytes in primary culture. J Neurochem 1995, 64:1965-1972.

57. Beckman JS, Koppenol WH: Nitric oxide, superoxide, and peroxynitrite: the good, the bad, and ugly. Am J Physiol 1996 27I:CI424-37.

58. Leist M, Fava E, Montecucco C, Nicotera P: Peroxynitrite and nitric oxide donors induce neuronal apoptosis by eliciting autocrine excitotoxicity. Eur J Neurosci 1997, 9: |488-|498.

59. Trackey JL, Uliasz TF, Hewett S]: SIN-I-induced cytotoxicity in mixed cortical cell culture: peroxynitrite-dependent and independent induction of excitotoxic cell death. I Neurochem 200I, 79:445-455.

60. Prusiner SB: Novel proteinaceous infectious particles cause scrapie. Science 1982, 216:136-144.

6I. Brown DR, Kretzschmar HA: Microglia and prion disease: a review. Histol Histopathol 1997, I 2:883-892.

62. Forloni G, Angeretti N, Chiesa R, Monzani E, Salmona M, Bugiani O Tagliavini F: Neurotoxicity of a prion protein fragment. Nature 1993, 362:543-546.
Publish with Biomed Central and every scientist can read your work free of charge

"BioMed Central will be the most significant development for disseminating the results of biomedical research in our lifetime. "

Sir Paul Nurse, Cancer Research UK

Your research papers will be:

- available free of charge to the entire biomedical community

- peer reviewed and published immediately upon acceptance

- cited in PubMed and archived on PubMed Central

- yours - you keep the copyright
BioMedcentral 